\title{
Sound Stimulates Labeling of Polyphosphoinositides in the Auditory Organ of the Noctuid Moth
}

\author{
Patricia L. Kilian and Jochen Schacht \\ Kresge Hearing Research Institute, University of Michigan, Ann Arbor, Michigan 48109, U.S.A.
}

\begin{abstract}
The Noctuid moth possesses a simple auditory structure suitable for the investigation of biochemical correlates of sound stimulation in vivo. Stimulation with pulsed tones increased ${ }^{3: 2} \mathrm{P}$ incorporation into polyphosphoinositides but not into ATP or other lipids. The effect was seen in the scoloparium (sensory structure) but not in the nodular sclerite, an adjacent nonsensory tissue. It was also not seen when the stimulus was a continuous tone, leading to adaptation of the action potential. Key words: Phospholipids-Phosphatidylinositol phosphate; biphosphate-Acoustic stimulation-Biopotentials.
\end{abstract}

Molecular changes concomitant with the electrophysiological events in stimulated auditory receptors are as yet unknown, at least partly for the lack of a suitable experimental model. For our purpose, an auditory structure is needed in which the electrophysiological detail of its response is sufficiently well defined and simple to permit a correlation with biochemical findings.

The ear of the Noctuid moth appears to meet these criteria. It is easily accessible and has a markedly simple morphology and electrophysiology. The sensory tissue, the scoloparium, contains two sensory cells along with a few supporting cells (Ghiradella, 1971). The sensory cells are true auditory receptors, of essentially similar physiological characteristics (Suga, 1961; Adams, 1971; Roeder, 1971). Only two types of bioelectric activity are induced by sound stimulation in these primary sensory cells: the generator or receptor potential, tantamount to the transduction event in the dendritic ends, and the action potential in the axonal segments. The preparation thus seemed well suited for an investigation of the role of polyphosphoinositides in hearing processes.

The polyphosphoinositides, phosphatidylinositol phosphate and phosphatidylinositol bisphosphate ${ }^{1}$, are quantitatively minor phos- pholipids of eukaryotic cells, but the turnover of their monoesterified phosphate groups is very rapid, as shown by ${ }^{32} \mathrm{P}$ radiotracer techniques. The rate of this turnover in neural tissue, the tissue in which these lipids primarily occur in mammals, is not invariant. Excitation of a variety of nerves and axons leads to changes in polyphosphoinositide metabolism (Birnberger et al., 1971; Schacht and Agranoff, 1972; Tret'jak et al., 1977; Abdel-Latif et al., 1978), and a phosphorylation and dephosphorylation cycle has been suggested as being associated with membrane permeability changes in axonal conduction (Griffin and Hawthorne, 1978; Kai and Hawthorne, 1969). In insects, polyphosphoinositides seem to have a widespread tissue distribution which includes nerves and sensory systems (Bridges, 1973; Kilian and Schacht, 1979).

We have previously proposed a mechanism for the transduction of acoustic energy into a generator potential by regulation of phosphorylationdephosphorylation reactions in the receptor membrane by sound energy (Kilian and Schacht, 1977). The polyphosphoinositides were suggested as candidates for this scheme, also, because studies with aminoglycosidic antibiotics suggested a specific role for these lipids in auditory phenomena. A change in turnover of these lipids after administration of
Address reprint requests to Dr. J. Schacht.

Present address of P.L.K. is Department of Molecular Biology, Eastern Pennsylvania Psychiatric Institute, Philadelphia, Pa. 19129.
Received July 2, 1979; accepted September 27, 1979.

1 1-(3-sn-Phosphatidyl)-D-myo-inositol 4-phosphate and 1-(3sn-phosphatidyl)-D-myo-inositol 4,5-bis(phosphate). 
neomycin or related ototoxic compounds has been shown in the cochlea of the guinea pig to correlate with a decrease in the microphonic potential (Stockhorst and Schacht, 1977; Nuttall et al., 1977).

We present here evidence that the ear of the Noctuid moth is a suitable experimental model and, further, that sound stimulation leads to specific changes of polyphosphoinositide labeling.

\section{MATERIALS AND METHODS}

Experiments were performed on laboratory-reared, male Agrotis ypsilon at $25^{\circ} \mathrm{C}$ in a soundproof room. The methodology has been described elsewhere (Kilian and Schacht, 1979). Briefly, the moths were temporarily anesthetized in ether vapor and their wings and legs were removed. The body of the moth was then pinned to a platform under a stereomicroscope so that the ear on the right side was clearly exposed. After denuding the area around the ear, $7 \mu$ l of carrier-free [ $\left.{ }^{32} \mathrm{P}\right]$ orthophosphate was injected into the air space below the epimeron adjacent to the tympanic air sac. Only tissues on the right side were analyzed. Other routes of injection of isotope lead to less efficient labeling of phospholipids in the ear. At various times following injection of the isotope, moths were killed by an injection of $10 \mu \mathrm{l}$ of glutaraldehyde followed immediately by $30 \mathrm{~s}$ of microwave irradiation at $1200 \mathrm{~W}$ (Litton 70/50). This procedure was most reliable for arrest of enzymatic activity and prevention of postmortem breakdown of the polyphosphoinositides. The ear tissues were dissected by hand and the scoloparium was removed, with a small piece of tympanic membrane attached to facilitate handling. Ten to twelve tissues were pooled for each analysis and a homogenate of guinea pig brain was added to the ear tissues as a source of carrier lipids. Phospholipids were extracted into acidified chloroform-methanol, separated by thin-layer chromatography, and located by autoradiography (Schacht, 1978). [32P]Nucleotide phosphate was analyzed by absorption on charcoal (Crane and Lipman, 1953).
For sound stimulation, a $75 \mathrm{~dB}$ (re: $20 \mu \mathrm{N} / \mathrm{m}^{2}$ ), $40 \mathrm{kHz}$ tone was delivered by a piezoelectric speaker (Eardrum, Los Angeles, California). One group of moths was stimulated from the time of injection of the isotope until they were killed ("tone") while another group were kept in silence ("no tone'). Prior to the selection of the acoustical stimulus, a threshold curve for the tympanic organ of Agrotis ypsilon had been obtained. The insect is most sensitive to ultrasonic frequencies, with highest sensitivity at $40-60 \mathrm{kHz}$ (Kilian and Schacht, 1977).

The statistical procedures used are described by Schefler (1969).

\section{RESULTS}

\section{Lipid Labeling}

Two tissues of the moth ear were analyzed: the scoloparium, containing the sensory cells, and the nodular sclerite, a strip of cuticle adjacent to the tympanic membrane. Phosphatidylinositol phosphate and bisphosphate were most rapidly labeled, reaching maximal ${ }^{32} \mathrm{P}$ incorporation at about $30 \mathrm{~min}$. Other quantitatively major phospholipids (phosphatidylserine, phosphatidylinositol, and phosphatidic acid) showed a slower rate of ${ }^{32} \mathrm{P}$ incorporation (Fig. 1).

\section{Sound Stimulation}

The effect of sound stimulation on ${ }^{32} \mathrm{P}$ labeling in the scoloparium was determined in five experiments (Table 1). The variability of the data was small when experiments were conducted in duplicate at the same time (Exp. $4 \mathrm{a}$ and $\mathrm{b} ; 5 \mathrm{a}$ and b) while the variability between experiments was larger. This variability may be due to seasonal variations since these experiments were conducted over a year.

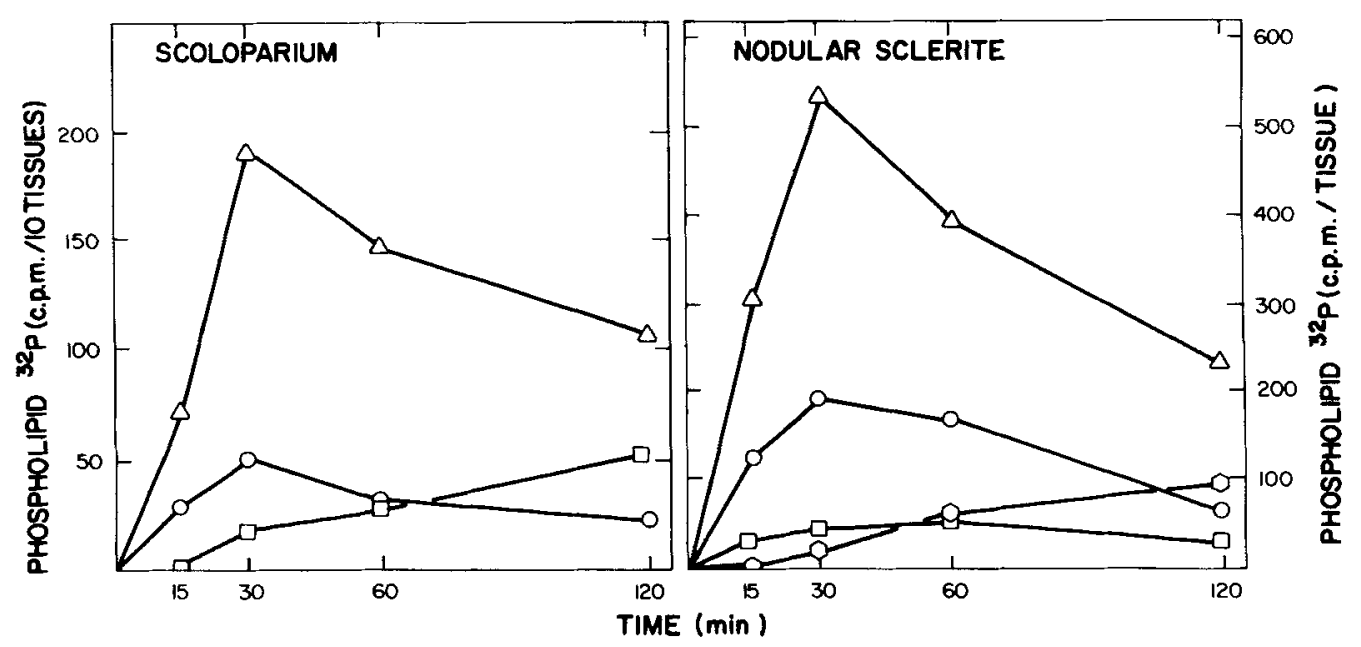

FIG. 1. Time-course of ${ }^{32} \mathrm{P}$-labeling. One hundred $\mu \mathrm{Ci}$ of ${ }^{32} \mathrm{P}_{\mathrm{i}}$ (carrier-free, in a volume of $7 \mu$ ) was injected into the moth as described in Methods. Moths were killed at times indicated, and 10 tissues were pooled for each point. ( $\square$ ), phosphatidic acid; (left, $\square$; right, $O$ ) phosphatidylinositol, phosphatidylserine; $(O)$, phosphatidylinositol phosphate; $(\Delta)$, phosphatidylinositol phosphate, bisphosphate. 
TABLE 1. ${ }^{32}$ P-labeling of the Noctuid moth ear(Scoloparium)

\begin{tabular}{|c|c|c|c|c|c|c|}
\hline \multirow[b]{2}{*}{ Exp. } & \multicolumn{2}{|c|}{$\mathrm{ATP}^{\prime \prime}$} & \multicolumn{2}{|c|}{$\mathrm{PhIP}^{b}$} & \multicolumn{2}{|c|}{$\mathrm{PhIP}_{2}{ }^{c}$} \\
\hline & No tone & Tone & No tone & Tone & No tone & Tone \\
\hline 1 & 18 & 17 & 6.0 & 12 & 19 & 36 \\
\hline 2 & 19 & 17 & 2.1 & 3.6 & 5.5 & 10 \\
\hline 3 & 10 & 13 & 5.3 & 8.7 & 15 & 27 \\
\hline $4 a$ & 12 & 11 & 7.2 & 6.4 & 19 & 20 \\
\hline b & 13 & 13 & 9.3 & 7.3 & 19 & 16 \\
\hline $5 a$ & 15 & 18 & 2.7 & 5.1 & 5.5 & 8.0 \\
\hline b & 16 & 18 & 4.3 & 4.4 & 7.3 & 8.5 \\
\hline
\end{tabular}

Moths received $150 \mu \mathrm{Ci}$ of ${ }^{32} \mathrm{P}$ (carrier-free, vol. $=7 \mu \mathrm{l}$ ) and were killed after $30 \mathrm{~min}(15 \mathrm{~min}$ in exp. 5). "Tone" groups were stimulated during this time with a pulsed tone signal $\left(40 \mathrm{kHz}, 75 \mathrm{~dB}\right.$ [re: $20 \mu \mathrm{N} / \mathrm{m}^{2}$ ], $50 \mathrm{~ms}$ on, $1 \mathrm{cycle} / \mathrm{s})$. Each value is from a pool of 10 to 12 tissues. Significance of differences between "no tone" and "tone" groups by $\chi^{2}$ ranking: $p<0.035$ for polyphosphoinositides.

" $\left.{ }^{32} \mathrm{P}\right]$ Nucleotide phosphate as percent of total soluble ${ }^{32} \mathrm{P}$.

b [ $\left.{ }^{32} \mathrm{P}\right]$ Phosphatidylinositol phosphate as percent of $\left[{ }^{32} \mathrm{P}\right]$ nucleotide phosphate.

${ }^{c}\left[{ }^{32} \mathrm{P}\right] \mathrm{Phosphatidylinositol} \mathrm{bisphosphate} \mathrm{as} \mathrm{percent} \mathrm{of}\left[{ }^{32} \mathrm{P}\right]$ nucleotide phosphate.

Seasonal differences in auditory studies were reported early by Yerkes (1905) and recently by Sewell et al. (1978). Sound stimulation did not significantly affect the labeling of ATP from ${ }^{32} \mathbf{P}_{i}$, but most experiments indicated an increase in ${ }^{32} \mathrm{P}$ incorporation into phosphatidylinositol phosphate and bisphosphate. Analysis of the data by $\chi^{2}$ ranking showed a significant difference between "tone" and "no tone" groups for the polyphosphoinositides.

In all of the experiments, labeling in the nodular sclerite was also measured. Since no active role in the hearing process has been ascribed to this structure, comparison of labeling in the two tissues in response to sound was made (Table 2). For each compound in each tissue, labeling in the presence of sound was expressed as the percentage of labeling without sound; i.e., a value of $100 \%$ indicates no effect of sound. Clearly, acoustic stimulation leads solely to changes in polyphosphoinositide labeling in the scoloparium. Labeling in the nodular sclerite remained unchanged with stimulation.

\section{DISCUSSION}

The increased labeling of polyphosphoinositides in the scoloparium during acoustic stimulation should be due to an enhanced rate of the turnover of the monoester phosphate groups of these lipids. While this conclusion cannot be reached unequivocally from our experimental data, it is supported by the fact that labeling of the precursor, ATP, was not stimulated. It is further supported by the finding that other labeled phospholipids in the scoloparium (phosphatidylinositol plus phosphatidic acid and phosphatidylserine) were not affected by sound. In addition, increased de novo synthesis can probably be ruled out since the contribution of this pathway to polyphosphoinositide labeling in the moth is very small for brief incubation times (Kilian and Schacht, 1979).

The increased labeling of polyphosphoinositides in only the sensory tissue suggests a specific correlation of these changes with a hearing-related process. Additional clues about the physiological role

TABLE 2. Effects of tone presentation on ${ }^{32} P$ labeling in scoloparium and nodular sclerite ${ }^{a}$

\begin{tabular}{lcc}
\hline & Scoloparium & Nodular sclerite \\
\hline ATP & $105 \pm 15$ & $102 \pm 23$ \\
Phosphatidylinositol phosphate & $142 \pm 50^{e}$ & $94 \pm 24$ \\
Phosphatidylinositol bisphosphate $^{\text {Other lipids }}{ }^{b}$ & $143 \pm 40^{d}$ & $91 \pm 24$ \\
\hline
\end{tabular}

${ }^{a}$ Labeling in the presence of stimulus as percent of labeling in its absence. Numbers are means \pm S.D. of five experiments.

${ }^{b}$ Labeled phosphatidic acid, phosphatidylinositol, and phosphatidylserine.

- The effect in scoloparium differs from nodular sclerite by $0.02<p<0.05$ (Wilcoxon) and $p=0.06$ (2-sample $t$-test). ${ }^{d}$ The effect in scoloparium differs from nodular sclerite by $p<0.01$ (Wilcoxon) and $p=0.02$ (2-sample $t$-test). Other differences not significant. 
are provided by comparing the effect of different tone stimuli. In the above experiments, the stimulus was a pulsed tone which initiates both generator and action potential activity in the auditory receptor of the moth. A continuous tone leads to rapid adaptation of spike activity, leaving the generator potential as the only bioelectric event (Adams and Belcher, 1974). Two preliminary radiotracer experiments indicate that the increased labeling observed with a pulsed tone is not seen with a continuous tone as a stimulus. In the latter case, average phosphatidylinositol phosphate was $2.9 \%$ (no tone) and $2.7 \%$ (continuous tone) of labeled ATP, while phosphatidylinositol bisphosphate was $11 \%$ and $10 \%$, respectively. Therefore, the changes in polyphosphoinositide labeling with stimulation by pulsed tone appear to correlate with spike activity in the acoustic receptor of the Noctuid moth rather than with generator potential activity.

These data are consistent with the hypothesis that polyphosphoinositides play a role in events related to neural excitation. Previous studies testing this hypothesis were carried out under nonphysiological conditions; e.g., isolated nerves and axons were presented with an inadequate stimulus (electrical stimulation). Such studies yielded conflicting results about the turnover of polyphosphoinositides (Salway and Hughes, 1972; White and Larrabee, 1973; White et al., 1974). Our study is a demonstration of changes in polyphosphoinositide labeling upon presentation of an adequate stimulus in an in vivo experiment. In addition, we have demonstrated that the auditory organ of the Noctuid moth can be used to analyze molecular events in hearing. The simplicity of this ear allows us to correlate electrophysiological, biochemical, and pharmacological investigations and makes it a suitable model for the study of auditory processes.

\section{ACKNOWLEDGMENT}

The authors wish to express their gratitude to the entomology department at the Agricultural Research and Development Center, Wooster, Ohio for supplying Agrotis ypsilon. This work was supported by a grant from the Deafness Research Foundation and by NIH Program Project grant NS 05785.

\section{REFERENCES}

Abdel-Latif A. A., Green K., Smith J. P., McPherson J. C., Jr., and Matheny J. L. (1978) Norepinephrine-stimulated breakdown of triphosphoinositide of rabbit iris smooth muscle: Effects of surgical sympathetic denervation and in vivo electrical stimulation of the sympathetic nerve of the eye. $J$. Neurochem. 30, 517-525.

Adams W. B. (1971) Intensity characteristics of the Noctuid acoustic receptor. J. Gen. Physiol. 58, 562-579.
Adams W. B. and Belcher E. O. (1974) Adaptation in the Noctuid acoustic receptor. J. Acoust. Soc. Am. 56, $\mathrm{S} 40$.

Birnberger A. C., Birnberger K. L., Eliasson S. G., and Simpson P. C. (1971) Effect of cyanide and electrical stimulation on phosphoinositide metabolism in lobster nerves. $J$. Neurochem. 18, 1291-1298.

Bridges R. G. (1973) The lipid composition of the larval nervous system of Musa domestica. A comparison between insects susceptible and resistant to cyclodiene insecticides. Comp. Biochem. Physiol. 44B, 191-203.

Crane R. K. and Lipman F. (1953) The effect of arsenate on aerobic phosphorylation. J. Biol. Chem. 201, 235-243.

Ghiradella H. (1971) Fine structure of the Noctuid moth ear. $J$. Morphol. 134, 24-46.

Griffin H. D. and Hawthorne J. N. (1978) Calcium-activated hydrolysis of phosphatidyl-myo-inositol 4-phosphate and phosphatidyl-myo-inositol 4,5-biphosphate in guinea-pig synaptosomes. Biochem. J. 176, 541-552.

Kai N. and Hawthorne J. N. (1969) Physiological significance of polyphosphoinositides in brain. Ann. NY Acad. Sci. 165, $761-773$.

Kilian P. L. and Schacht J. (1977) Phospholipid labeling in the Noctuid moth ear: A model for biochemical studies of transduction, in Inner Ear Biology/Biologie de l'oreille interne (Portmann M. and Aran J.-M., eds) Coll. INSERM 68, $167-178$.

Kilian P. L. and Schacht J. (1979) Polyphosphoinositides in insect muscle and sensory tissues. J. Neurochem. 32, 247-248.

Nuttall A. L., Marques D. M., and Lawrence M. (1977) Effects of perilymphatic perfusion with neomycin on the cochlear microphonic potential in the guinea pig. Acta Otolaryngol. [Stockh] 83, 393-400.

Roeder K. R. (1971) Acoustic alerting mechanisms in insects. Ann. NY Acad. Sci. 188, 63-79.

Salway J. G. and Hughes I. E. (1972) An investigation of the possible role of phosphoinositides as regulators of action potentials by studying the effect of electrical stimulation. tetrodotoxin and cinchocaine on phosphoinositide labeling by ${ }^{32} \mathrm{P}$ in rabbit vagus. $J$. Neurochem. $19,1233-1240$.

Schacht J. (1978) Purification of polyphosphoinositides by chromatography on immobilized neomycin. J. Lipid Res. 19, $1063-1067$.

Schacht J. and Agranoff B. W. (1972) Phospholipid labeling by ${ }^{32} \mathrm{P}$-orthophosphate and ${ }^{3} \mathrm{H}$-myo-inositol in the stimulated goldfish brain in vivo. J. Neurochem. 19, 1417-1421.

Schefler W. C. (1969) Statistics for the Biological Sciences, pp. 68-136. Addison-Wesley Publishing Co., Reading, Mass.

Sewell W. F., Norris C. H., Tachibana M., and Guth P. S. (1978) Detection of an auditory nerve-activating substance. Sc $i$ ence 202, 910-911.

Stockhorst E. and Schacht J. (1977) Radioactive labeling of phospholipids and proteins by cochlear perfusion in the guinea pig and the effect of neomycin. Acta Otolaryngol. [Stockh] 83, 401-409.

Suga N. (1961) Functional organization of the two tympanic neurons in Noctuid moths. Jpn. J. Physiol. 11, 666-677.

Tret'jak A. G., Limarenko I. M., Kossova G. V., Gulak P. V., and Kozlov Yu. P. (1977) Interrelation of phosphoinositide metabolism and ion transport in crab nerve fibers. $J$. Neurochem. 28, 199-205.

White G. L. and Larrabee M. G. (1973) Phosphoinositides and other phospholipids in sympathetic ganglia and nerve trunks of rats. J. Neurochem. 20, 783-798.

White G. L., Schellhase H. U., and Hawthorne J. N. (1974) Phosphoinositide metabolism in rat superior cervical ganglion, vagus and phrenic nerve: Effects of electrical stimulation and various blocking agents. J. Neurochem. 22, $149-158$.

Yerkes R. M. (1905) The sense of hearing in frogs. J. Comp. Physiol. Psychol. 15, 279-304. 